\title{
A giant ureteral stone in a 32-year-old man: a case report
}

\section{Mohammad Natami' \\ Alireza Makarem² \\ Faisal Ahmed ${ }^{2}$ \\ Niloofar Dastgheib ${ }^{3}$ \\ Ali-hossein Zahraei ${ }^{3}$}

'Department of Urology, Hormozgan University of Medical Science, Bandar Abbas, Iran; ${ }^{2}$ Department of Urology, Shiraz University of Medical Science, Shiraz, Iran; ${ }^{3}$ Department of Urology, Shiraz University of Medical Science, Shiraz, Iran

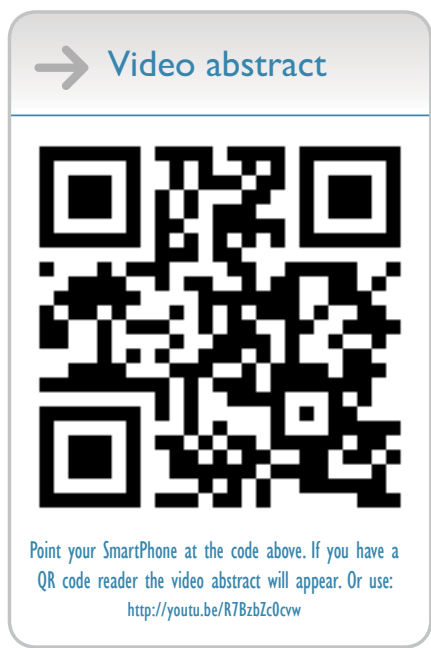

Correspondence: Alireza Makarem Department of Urology, Shiraz University of Medical Science, Faghihi Hospital, Zand Street, Shiraz, Iran

Tel/fax $+987 / 32326645$

Email alirezamakarem200I@gmail.com
This article was published in the following Dove Medical Press journal: International Medical Case Reports Journal

\begin{abstract}
Giant ureteral calculi are defined as stones greater than $5 \mathrm{~cm}$ in length or circumference. These giant calculi can cause blockage of the ureter, dilation of the kidney and also decreased kidney function if not treated in time. The patient in this report presented with complaints of bilateral episodic pain of the bilateral lumbar region. Kidney, ureter and bladder (KUB) X-ray test showed a large bilateral ureteral stone about $14 \mathrm{~cm}$ in length and $106 \mathrm{~g}$ weight in the left ureter and $3 \mathrm{~cm}$ longitudinal diameter in the right ureter and also a staghorn stone in the left upper collecting system. Thereafter, the ureteric calculi were managed successfully using the combination of open and endoscopic techniques.
\end{abstract}

Keywords: ureteric calculus, ureterolithotomy, transurethral lithotripsy

\section{Introduction}

Ureteral stones are a common complaint in primary care centers. Renal colic and hematuria are the classic symptoms, while abdominal or flank pain, urinary urgency, nausea, frequency and difficulty of urinating, testicular or penile pain are atypical symptoms of the ureteral stones. ${ }^{1}$ Eighty percent of the stones are composed of calcium oxalate or calcium phosphate. Others may be Struvite (magnesium ammonium phosphate), uric acid, and cysteine stones. ${ }^{2}$

The likelihood of spontaneous passage of the ureteral stones is associated with both location (proximal, mid, and distal ureter) and size of the stone. ${ }^{3}$ Ureteric calculi are usually small, but can grow larger in size gradually. Two factors exist that increase the stone diameters: first, stone impaction and aggregation of crystals, and the second cause is distal ureteral obstruction. ${ }^{4}$ If stones grow to sufficient size of $3 \mathrm{~mm}$ or more, they can cause blockage of the ureter which is the main cause of clinical symptoms. ${ }^{5}$ Ureter blockage can also lead to dilation of the kidney and decreased kidney function. ${ }^{6}$ The term giant ureteric calculus has been used for ureteric stones, which exceed $5 \mathrm{~cm}$ in length, circumference or weighing more than $50 \mathrm{~g} .^{7}$

Based on the prior studies, the spontaneous passage rate as a function of stone size was $87 \%$ for stones $1 \mathrm{~mm}$ in diameter; $76 \%$ for stones $2-4 \mathrm{~mm}$; $60 \%$ for stones $5-7$ $\mathrm{mm}$; $48 \%$ for stones $7-9 \mathrm{~mm}$; and $25 \%$ for stones larger than $9 \mathrm{~mm} .{ }^{8,9}$ In addition, spontaneous passage rate was more likely to be for distal and ureterovesical junction stones than stones in the proximal ureter or mid-ureteral stones. ${ }^{9}$

In this study, we report a case of large bilateral ureteral stones with $14 \mathrm{~cm}$ length and $106 \mathrm{~g}$ weight in the left side and $3 \mathrm{~cm}$ longitudinal diameter in the right side with a complete staghorn stone in the left upper collecting system. 


\section{Case report}

A 32-year-old male patient presented on March 14, 2015 with complaints of bilateral episodic pain of the bilateral lumbar region for 6 months. The history of his illness indicated that the patient used opium to reduce his pain. No significant medical or family history was mentioned and the laboratory findings were as follows: Hemoglobin: $14.6 \mathrm{~g} / \mathrm{dL}$, Blood urea nitrogen: $18 \mathrm{mg} / \mathrm{dL}$, Creatinine: $1.3 \mathrm{mg} / \mathrm{dL}, \mathrm{Na}: 142 \mathrm{~m}$ $\mathrm{mol} / \mathrm{L}, \mathrm{K}: 3.9 \mathrm{mmol} / \mathrm{L}$, serum calcium: $9 \mathrm{mg} / \mathrm{dL}$, and serum phosphorus: $3.5 \mathrm{mg} / \mathrm{dL}$. Results of his physical examination on admission were unremarkable.

According to the clinical symptoms, the kidney, ureter and bladder (KUB) X-ray test was ordered. Findings illustrated a huge left distal ureteral calculus with $14 \mathrm{~cm}$ length and $106 \mathrm{~g}$ weight, a large right ureteral calculus with $3 \mathrm{~cm}$ longitudinal diameter and also an opaque staghorn stone in the left kidney (Figure 1). The total weight of these stones was more than $300 \mathrm{~g}$. Although excretion was reduced slightly in the right kidney, his overall renal function was normal and acceptable excretion was observed on the left side.

We employed the combination of open and endoscopic technique for treatment of this special case of ureteral stone. The patient underwent right side transurethral lithotripsy
(TUL) and left open ureterolithotomy through the Gibson incision to remove the giant uretric calculus. Longitudinal incision was performed on the ureteral wall to remove the stone from the left ureter and the stone was extracted with difficulty due to its angle and impaction to the ureteral wall. Thereafter, the distal part of the left ureter was resected due to distal stenosis and then uretroscopy was performed through the resected ureter with advancement to the proximal part of the ureter; as we reached to the renal pelvis stone, it was fragmented. In fact, the retrograde intrarenal surgery (RIRS) was performed for three main goals: reducing the bulk of the stone, applying ureteral stents to ensure the patency of the ureter and facilitating percutaneous nephrolithotomy (PCNL) for the next surgery.

Two weeks after the first surgery, in the second session, PCNL was conducted to remove the remaining kidney stones and then the patient was transferred to the ward for subsequent observation and management. The patient was discharged a few days later.

\section{Discussion}

To the best of our knowledge, only 13 case reports of ureteral calculi measuring $12 \mathrm{~cm}$ or more have been previously

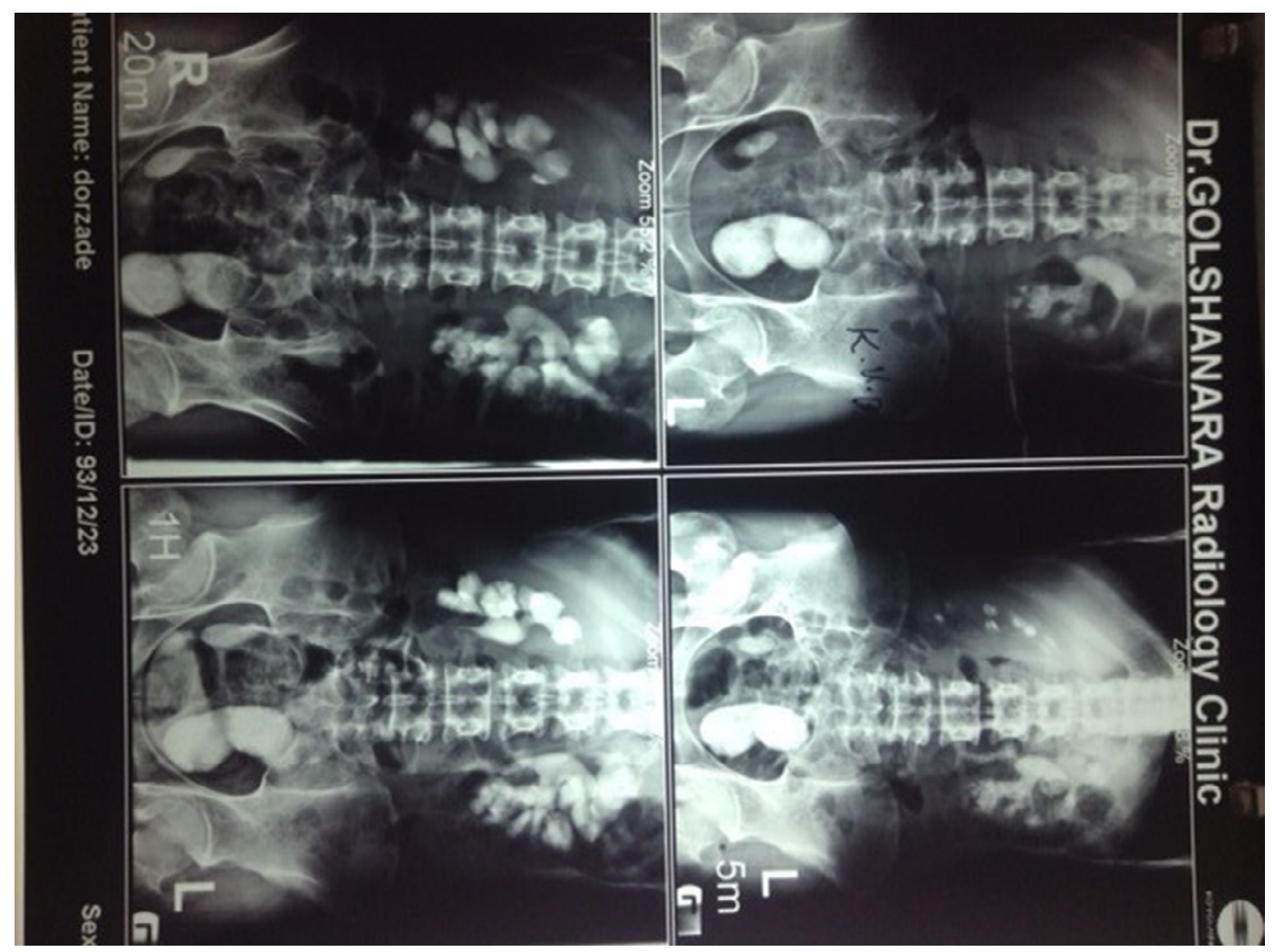

Figure I Kidney, ureter and bladder X-ray showing bilateral ureteric calculi; a huge distal ureteral calculus and an opaque staghorn stone in the left side and also a large right ureteral calculus. 
published. Therefore, giant ureteric stones are rare. Another rarity of its incidence was due to the normal renal function of the patient, whereas in most cases, the kidney above the stone is functionless. ${ }^{7,10}$

Although the longest stone was reported by Taylor in 1934 which was $21.5 \mathrm{~cm}$ in length, the stone reported in the present article was one of the largest ureteral calculi so far reported in the world (Figure 2). ${ }^{11}$ Before the present document, Mayer indicated the largest ureteral stone $(11 \times 5.5 \times 5 \mathrm{~cm})$, which weighed 286 g. ${ }^{7,12}$ Another study also reported a giant stone with $13 \mathrm{~cm}$ of length and $90 \mathrm{~g}$ of weight. ${ }^{13}$

Most of these giant stones were distal ureteral calculi. This may be due to their role in distal ureteral obstruction, which is a factor that increases the diameter of the stone. ${ }^{14}$ The majority of small stones with relatively mild hydronephrosis (HDN) can be managed with acetaminophen. ${ }^{15}$ However, according to the size and location of the stones, about $20 \%$ of the stones require surgical operation. ${ }^{16}$ There are various techniques in the management of ureteral stones, including extracorporeal shock wave lithotripsy (ESWL), open surgery, medical expulsive therapy (MET), ureteroscopy (URS), laparoscopy (LAP), and PCNL. ${ }^{17}$ Drainage with an internal ureteral stent is also common due to its positive effects on morbidity. ${ }^{18}$ In this regard, we introduced the combination of open and endoscopic techniques for treatment of the patient. Nowadays, ESWL and PCNL are the two most commonly performed treatments since they are minimally invasive surgical methods that significantly decrease the morbidity of stone removal. ${ }^{19}$ In these techniques, success is determined by fragmentation rates and the size of the remaining stone fragments. $^{20}$

In the diagnosis of ureteral stones, the clinical diagnosis should be supported by an appropriate imaging procedure. Computed tomography (CT) is now the first line imaging technique to confirm the diagnosis of a urinary stone. In

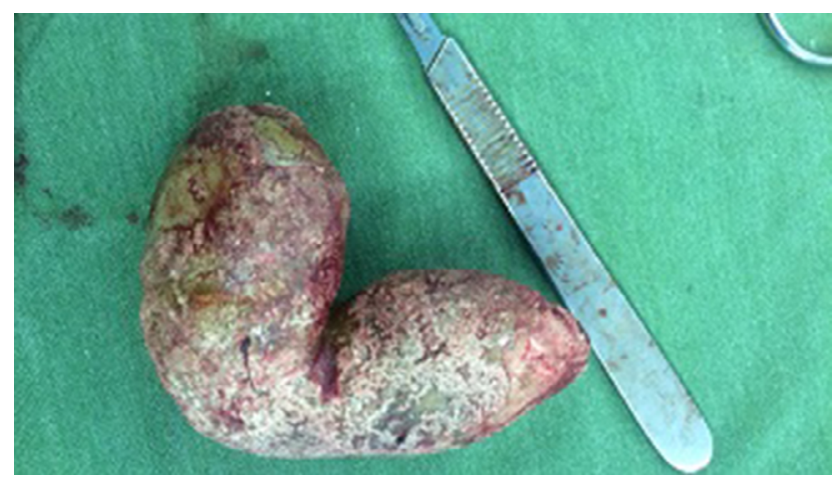

Figure 2 Extracted giant ureteral stones measuring $14 \mathrm{~cm}$ in length and $106 \mathrm{~g}$ in weight in the left ureter. addition, the KUB study is an X-ray procedure that assesses the organs of the urinary system. It can also identify kidney stones and certain types of gallstones. ${ }^{21}$

\section{Ethics statement}

We declare that our study was approved by the ethics committee of Hormozgan University of Medical Sciences, Hormozgan, Iran. Additionally, written informed consent was provided by the patients to have the case details and any accompanying images published, the safety of our procedure, and its probable complications.

\section{Acknowledgment}

The authors would like to thank Shiraz University of Medical Sciences, Shiraz, Iran and also Center for Development of Clinical Research of Nemazee Hospital and Dr Nasrin Shokrpour for editorial assistance.

\section{Author contributions}

All authors contributed to data analysis, drafting or revising the article, gave final approval of the version to be published, and agree to be accountable for all aspects of the work.

\section{Disclosure}

The authors report no conflicts of interest in this work.

\section{References}

1. Matlaga BR, Jansen JP, Meckley LM, Byrne TW, Lingeman JE. Treatment of ureteral and renal stones: a systematic review and meta-analysis of randomized, controlled trials. J Urol. 2012;188(1):130-137.

2. Hammady A, Gamal WM, Zaki M, Hussein M, Abuzeid A. Evaluation of ureteral stent placement after retroperitoneal laparoscopic ureterolithotomy for upper ureteral stone: randomized controlled study. $J$ Endourol. 2011;25(5):825-830.

3. Perez Castro E, Osther PJS, Jinga V, et al; CROES Ureteroscopy Global Study Group. Differences in ureteroscopic stone treatment and outcomes for distal, mid-, proximal, or multiple ureteral locations: the clinical research office of the Endourological Society Ureteroscopy Global Study. Eur Urol. 2014;66(1):102-109.

4. Lidén M, Andersson T, Broxvall M, Thunberg P, Geijer H. Urinary stone size estimation: a new segmentation algorithm-based CT method. Eur Radiol. 2012;22(4):731-737.

5. Wang Y-H, Zhu Y-S, Yang J-Q, et al. Application of ultrasonography in the diagnostic of ureteris obstruction of transplanted kidneys. Acta Academiae Medicinae CPAF. 2008;12:016.

6. Swenson DW, Darge K, Ziniel SI, Chow JS. Characterizing upper urinary tract dilation on ultrasound: a survey of North American pediatric radiologists' practices. Pediatr Radiol. 2015;45(5):686-694.

7. Rathod R, Bansal P, Gutta S. A giant ureteric calculus. Indian J Urol. 2013;29(3):263.

8. Osorio L, Lima E, Autorino R, Marcelo F. Emergency management of ureteral stones: recent advances. Indian J Urol. 2008;24(4):461.

9. Coll DM, Varanelli MJ, Smith RC. Relationship of spontaneous passage of ureteral calculi to stone size and location as revealed by unenhanced helical CT. AJR Am J Roentgenol. 2002;178(1):101-103.

10. Banerji JS, Devasia A. Giant ureteric calculus. ANZ J Surg. 2011;81(9):653-654. 
11. Taylor WM. Large ureteral calculi. Report of a case. The Journal of Urology. 1934;32(1):93-102.

12. Mayers MM. A Giant Ureteral Calculus (Weight: 286 Grams). The Journal of Urology. 1940;44(1):47-53.

13. Sabnis RB, Desai RM, Bradoo AM, Punekar SV, Bapat SD. Giant ureteral stone. J Urol. 1992;148(3):861-862.

14. Beliaev AM, Beaven T, Koya MP. Spontaneous passage of a very large ureteral stone. ANZ J Surg. 2016;86(12):1063-1064.

15. Falahatkar S, Khosropanah I, Allahkhah A, Jafari A. Open surgery, laparoscopic surgery, or transureteral lithotripsy-which method? Comparison of ureteral stone management outcomes. J Endourol. 2011;25(1):31-34.

16. Semins MJ, Shore AD, Makary MA, et al. The association of increasing body mass index and kidney stone disease. J Urol. 2010;183(2) 571-575.
17. Cui Y, Cao W, Shen H, et al. Comparison of ESWL and ureteroscopic holmium laser lithotripsy in management of ureteral stones. PLoS One. 2014;9(2):e87634.

18. Berent AC, Weisse CW, Todd K, Bagley DH. Technical and clinical outcomes of ureteral stenting in cats with benign ureteral obstruction: 69 cases (2006-2010). J Am Vet Med Assoc. 2014;244(5):559-576.

19. Oberlin DT, Flum AS, Bachrach L, Matulewicz RS, Flury SC. Contemporary surgical trends in the management of upper tract calculi. $J$ Urol. 2015;193(3):880-884.

20. Turunc T, Kuzgunbay B, Gul U, et al. Factors affecting the success of ureteroscopy in management of ureteral stone diseases in children. $J$ Endourol. 2010;24(8):1273-1277.

21. Berkovitz N, Simanovsky N, Katz R, Salama S, Hiller N. Coronal reconstruction of unenhanced abdominal CT for correct ureteral stone size classification. Eur Radiol. 2010;20(5):1047-1051.
International Medical Case Reports Journal

\section{Publish your work in this journal}

The International Medical Case Reports Journal is an international, peer-reviewed open-access journal publishing original case reports from all medical specialties. Previously unpublished medical posters are also accepted relating to any area of clinical or preclinical science. Submissions should not normally exceed 2,000 words or

\section{Dovepress}

4 published pages including figures, diagrams and references. The manuscript management system is completely online and includes a very quick and fair peer-review system, which is all easy to use. Visit $\mathrm{http}: / /$ www.dovepress.com/testimonials.php to read real quotes from published authors.

Submit your manuscript here: https://www.dovepress.com/international-medical-case-reports-journal-journal 